\title{
Expansão da educação superior e da edu- cação profissional no Brasil: tensões e perspectivas $^{1}$
}

Domingos Leite Lima Filho Universidade Tecnológica Federal do Paraná

\section{Resumo}

O texło analisa a expansão da educação superior e da educação profissional no Brasil no período de 1995 a 2014. Procedeu-se àanálise documental e revisão bibliográfica da temática e adotou-se o referencial teórico-metodológico do materialismo histórico para identificar o sentido e significado desse movimento de expansão no contexto neoliberal de redefinição do papel do Estado. Constatou-se que as políticas educacionais que realizam essa expansão apresentam elementos de continuidade que evidenciam o processo de privatização mediante a utilização do financiamento público e de formas de regulação do Estadopara induzir o fortalecimento do mercado educacional.

Palavras-chave: Educação superior. Educação profissional. Políticas educacionais.

\section{Expansion of higher education and vocational education in Brazil: tensions and perspectives}

\section{Abstract}

The text analyzes the expansion of higher education and vocational education in Brazil using the methodology of document analysis and literature review, based on theoretical references of historical materialism. Identify the meaning and significance of this movement in the context of neoliberal redefinition of the role of the State. It concludes that educational policies that perform this expansion have elements of continuity that show that the privatization process through the use of public funding and forms of state regulation lead the strengthening of an educational market.

Keywords: Higher education. Professional education. Educational policies. 
Expansão da educação superior e da educação profissional no Brasil:tensões e perspectivas

\section{Expansión de la educación superior y profesional en Brasil: tensiones y perspectivas}

\section{Resumen}

El texto analiza la expansión de la educación superior y la formación profesional en el Brasil utilizando la metodología de análisis de documentos y revisión de la literatura, con base en el marco teórico del materialismo histórico. Identifica el significado de este movimiento en el contexto neoliberal de redefinición del papel del Estado y concluye que las políticas educativas que realizan dicha expansión muestran elementos de continuidad y sostienen el proceso de privatización a través de la utilización de los fondos públicos yformas de regulación estatal para inducir el establecimiento de un mercado educacional.

Palabras clave: Educación superior. Formación profesional.Política educativa.

Analisar a expansão da educação superiore da educação profissional no atual contexto brasileiro, procurando identificar e problematizar em torno 196 das tensões, desafios e perspectivas que envolvem a questão, é um tema da mais alta relevância e complexidade, tanto para orientar a nossa ação como pesquisadores, envolvidos com o desenvolvimento de pesquisas e produção do conhecimento na área, quanto para orientar nossa ação profissional e social, vistoque somos trabalhadores e cidadãos diretamente envolvidos com questões relativas à concepção e implantação de políticas públicas que tratam da garantia do direito subjetivo à educação.

Discutir os sentidos e significados da reforma educacional da qual a expansão da educação superior e da educação profissional fazem parte implica a necessidade de falar da identidade e papel social da universidade pública e também das instituições públicas de educação profissional. Falar em identidade exige falar em história, reconhecimento por parte da sociedade e autorreconhecimento da instituição e de seus sujeitos. Falar em papel social pressupõe necessariamente entender a instituição e a rede pública no contexto da sociedade em que ela está constituída, e da qual é também sujeito constituinte, portanto exige examinar o modelo e a dinâmica desta sociedade e relacioná-los à atuação das instituições em exame. Implica, ainda,ter, como referência, a história da formação social brasileira e sua realidade atual, 
observando, nesse contexto, os desafios que se põem à sociedade na perspectiva de uma educação universalizada e da produção de ciência e tecnologia de qualidade socialmente referenciada que se insira na construção de uma sociedade democrática e de sujeitos autônomos e críticos.

A problemática educacional não se encerra em si mesma e, dessa forma, a questão da identidade e do papel social da universidade pública e da educação profissional pública é complexa, visto que os modelos educacionais e as políticas educacionais que the dão suporte somente se tornam plenamente compreensíveis se referidos ao modelo societário do qual fazem parte e no qual se encontram sua explicação, justificação e também os seus elementos contraditórios. Cabe, assim, perguntar: Na perspectiva da construção de uma sociedade democrática e de sujeitos autônomos e críticos quais são as demandas educacionais? Que prioridades sociais se apresentam?

Em razão de um modelo social historicamente excludente e concentrador de renda, a sociedade brasileira produziu e acumulou, ao longo de séculos, forte exclusão social e educacional. Não será necessário mencionar aqui dados estatísticos educacionais e sociais atestadores dessa exclusão. São indicadores sociais negativos de uma sociedade marcada pela desigualdade, que se abatem também de forma desigual sobre a população e, óbvio, os principais prejudicados são os trabalhadores, as camadas populares e mais pobres, historicamente excluídas da etapa final da educação básica, da educação superior e da formação profissional pública e de qualidade. A magnitude e gravidade social dessa exclusão são amplamente conhecidas e indicam que a expansão educacional, em particular a expansão da educação pública, em todos os níveis e modalidades é não somente desejada, reivindicada, mas, sobretudo, socialmente necessária.

Portanto, há razões de sobra para sereivindicar a expansão como política pública. Mas a questão é que não é qualquer expansão, é precisodiscutir: qual o sentido e significado da expansão, suas características, intenções? A que e a quem servem?

A discussão aprofundada da expansão da educação superior pode se realizar mediante a análise de grandes temas, tais como: o financiamento, a organização institucional e acadêmica, a avaliação, o trabalho docente, oacesso e permanência, a produção do conhecimento e a educação superior do campo, entre outros ${ }^{2}$. A observação desses mesmos temas é igualmente 
Expansão da educação superior e da educação profissional no Brasil:tensões e perspectivas

pertinente quando se examina a problemática da expansão da educação profissional e, sobretudo, quando é analisadaesta última em sua relação com a educação básica e a educação superior.

Embora cada um desses processos ou movimentos de reforma e expansão da educação superior e da educação profissional contenha singularidades e especificidades, formas de materialização e desdobramentos que demandam análises específicas, entende-seque a análise conjunta dos mesmos é interessante e tem a potencialidade de contribuir com a identificação e compreensão do sentido e significado da orientação geral do Estado brasileiro com vistas às políticas públicas, especialmente aquelas que vão além do limite da educação básica. $\bigcirc$ argumento central apresentado, a seguir, a partir dessa tentativa de análise conjunta aqui esboçada, é que esses dois movimentos evidenciam, com clareza, um processo de privatização do Estado, que se materializa, dentre outras evidências, pela transformação da educação em mercadoria e pela constituição e fortalecimento, com incentivo direto do financiamento público e mediante formas de regulação do Estado, de um ramo de negócio, o mercado da educação, em particular, da educação superior e da educação profissional. Ademais, nessa análise e argumentação, procurar-se-

198 -á oferecer evidências de que esses dois movimentos, no período que vai de 1995 a 2014 , apresentam muito mais elementos de continuidade e endurecimento, do que de descontinuidade e esmaecimento.

\section{A reforma do Estado e a educação sob a ótica neoliberal}

É importante situar as reformas educacionais e a expansão privatizante e mercantil da educação nos marcos da política neoliberal de redefinição da concepção e papel do Estado, que assume caráter hegemônico nos países centrais do capitalismo a partir dos anos 1980 e no Brasil a partir dos anos 1990. Nesse contexto, assumem centralidade ideias-chave que irão orientar a reforma do Estado, tais como o livre mercado (liberação plena dos meios e processos, concorrência e competitividade), o neoconservadorismo ${ }^{3}$ (modernização conservadora, Estado frouxo no controle dos fluxos de capital e forte na regulação de políticas sociais e no estabelecimento de programas sociais de compensação e assistência) e o neopragmatismo ${ }^{4}$, às quais, no Brasil, unem-se a herança patrimonialista e o populismo autoritário. 
Situando esse quadro no que denomina de "[...] agenda pós-moderna [...]", Moraes (2004, p. 351 ) alerta para os efeitos de despolitização e cooptação que exercem sobre a educação e as políticas educacionais, na medida em que tais orientações postulam um "[...] nexo direto entre educação e a recelebração das virtudes do mercado [...]" e buscam promover o "[...] ocultamento da face fortemente excludente do consenso, das maneiras efetivas da dominação e da exclusão."

Tais elementos conceituais demarcam a ação do Estado e orientam e subordinam as políticas públicas pelo domínio do campo econômico, destacando-se valores como eficácia, eficiência, performatividade, competitividade, taxas de investimento e retorno, prestação de contas e avaliação. A hegemonia conservadora e neoliberal lançará mão dessas ideias-chave e valores como justificadores ideológicos e motivadores práticos decisivos para a implantação das reformas do Estado no Brasil a partir dos anos de 1990. Orientadas pelo trinômio da desregulamentação, flexibilização e privatização, as reformas redefinem aspolíticas e a ação das instituições públicas, passando a exigir delasuma maior produtividade e abertura, ou seja, produzir mais com menos recursos, e vínculo estreito com a economia na indústria, no comércio e nos serviços.

Nesse contexto, ganham destaque as concepções de Estado gestor e avaliador, com desenvolvimento de tecnologias gerenciais de poder e mecanismos de controle burocrático e de regulação das políticas e das instituições. Mas, não somente das políticas e das instituições, pois a "eficiência"e "eficácia" daqueles mecanismos também exigem sua aplicação nos e pelos funcionários dessas instituições. Conforme analisam João dos Reis da Silva Júnior e Valdemar Sguissardi, já em 1995, o então Ministro da Administração Federal e da Reforma do Estado, Luiz Carlos Bresser Pereira, enunciava o perfil desejado para o funcionário público, de acordo com os pressupostos da reforma em implantação:

[...] um trabalhador socialmente transformado à imagem e semeIhança do trabalhador da iniciativa privada. Ele deixa de ter a prerrogativa de funcionário do Estado - não produtor de mais-valia e prestador de serviços estatais públicos em benefício dos direitos do cidadão - para tornar-se um prestador de serviços, com a competência de sua formação de toda a vida, a vender seu trabalho objetivo ao Estado e às instituições estatais públicas ou às instituições estatais mercantis (SILVAJÚNIOR;SGUISSARDI, 1999, p. 34). 
Expansão da educação superior e da educação profissional no Brasil:tensões e perspectivas

A análise aprofundada desse processo evidencia que é preciso levar a efeitoque o Estado expressa, no plano jurídico e formal, a hegemonia e as relações sociais fundamentais do sistema social, de forma a atender às necessidades orgânicas do capital, cambiantes ao longo da história, e que, nas determinadas conjunturas, buscam adequação e reformas no sentido de preservação das melhores condições de reprodução ampliada e acumulação do capital. É nesse contexto que emergem mundialmente a partir dos anos de 1980 a hegemonia das políticas neoliberais e, nessa perspectiva, as políticas públicas que se realizam em conjunturas de redefinição da estrutura e do papel do Estado, como as verificadas no Brasil a partir dos anos 1990, expressam, igualmente, requerimentos da ordem do capital e do ajuste das estruturas de poder predominantes na sociedade brasileira a esse contexto histórico.

É esse o contexto em que se localiza e se origina a mercantilização da universidade pública, dos Centros Federais de Educação Tecnológica (Cefets) e escolas técnicas, dentre outras instituições educacionais, e é tendo como pano de fundo essa demarcação que se irábuscar apreender o sentido e significado da reforma e expansão da educação superior e da educação profissional.

\section{A reforma e expansão da educação superior}

A Lei de Diretrizes e Bases da Educação Nacional (LDB, Lei n 9.394 de 20 de dezembro de 1996) e o Plano Nacional de Educação 20012010 (PNE, Lei n 10.172, de9 de janeiro de 2001) aprovados no governo Cardoso foram demarcadores da orientação geral das reformas educacionais em curso. Para a educação superior, o referido PNEestabelecia diretrizes e metas relativas à expansão para o período 2001-2010, mediante estratégias de diversificação de instituiç̃̃es e modalidades de cursos presenciais e a distância, com ênfase nestes últimos, bem como a importância de processos de avaliação de qualidade baseados em critérios de eficiência e eficácia. Ao mesmo tempo que o PNE não estabelecia compromissos e mecanismos de financiamento público da educação superior, induzia a interpenetração entre as esferas pública e privada na gestão e sustentação das instituições.

A análise desses dois instrumentos normativos centrais das políticas educacionais conduzidos pelo Estado brasileiro mostra a vinculação de suas 
concepções às orientações preconizadas pelos organismos internacionais no cenário global de reestruturação do capital. Nesse sentido, a lógica que presidirá a reestruturação e expansão da educação superior será concernente com esse ideário:

A educação superior no Brasil é emblemática na medida em que se reestrutura, rompendo com o princípio da indissociabilidade entre ensino, pesquisa e extensão, por meio de ações deliberadas em prol de um crescente processo expansionista, balizado por políticas indutoras de diversificação e diferenciação institucional, o qual, no caso brasileiro, tem significado uma expansão pautada, hegemonicamente, pelo aligeiramento da formação e pela privatização desse nível de ensino (DOURADO, 2002, p. 245).

Em síntese, diversas pesquisas sobre as políticas educacionais e reforma do Estado na década de 1990 (SILVAJÚNIOR; SGUISSARDI, 2000; CATANI; OLIVEIRA, 2000; DOURADO, 2002) aproximam-se nas conclusões de que a reestruturação e a expansão da educação superior no Brasil nos anos de 1990 ocorreram mediante intensificação dos processos de diversificação e diferenciação institucional consubstanciados por um amplo movimento de privatização e minimização do Estado ante as instituições e políticas públicas.

As mudanças na educação superior fazem-se por meio de uma matriz teórico-político-ideológica que mantém proximidade com a que opera no interior do aparelho do Estado, tendo como pano de fundo as mudanças na produção e a expansão do capital, onde de fato se operam as redefinições das esferas pública e privada, destacando-se a expansão desta e a restrição daquela na presente reconfiguração deste nível de ensino (SILVA JÚNIOR;SGUISSARDI, 2000, p. 1031.

Os instrumentos normativos, políticas e programas governamentais relativos à reformulação e expansão do ensino superior brasileiro que vieram a ser implementados, ao longo dos anos 2000, guardaram conformidade com a concepção e lógica estabelecidas na década anterior e trataram de dar-thes continuidade e materialidade. Dentre esses, destacam-se como principais:o Fundo de Financiamento do Ensino Superior (Fies), o Programa Universidade para Todos (Prouni), a Universidade Aberta do Brasil (UAB), o Programa de Apoio a Planos de Reestruturação e Expansão das Universidades Federais 
Expansão da educação superior e da educação profissional no Brasil:tensões e perspectivas

(Reuni) e a criação dos Institutos Federais de Educação, Ciência e Tecnologia (IFs).

Fies, criado em 1999 e convertido em Lei, em 2001, é destinado a financiar mensalidades para graduação na educação superior de estudantes matriculados em instituições privadas. A partir de 2012, o Fiespassou a sedenominar Fundo de Financiamento Estudantil efoi ampliado para atender tambémaofinanciamento de cursos técnicos de formação inicial, de nível médio, pós-médio e superiores de tecnologia. $\bigcirc$ Prouni, criado em 2004 e convertido em Lei, em 2005, tem como objetivoa concessão de bolsas de estudos integrais e parciais (de 50\% e de 25\%) aos estudantes de graduação em instituições privadas de ensino superior, sendo elas com ou sem fins lucrativos.

A Universidade Aberta do Brasil (UAB), instituída em 2006, está voltada para o desenvolvimento do ensino superior a distância com o propósito de expandir e interiorizar a oferta de cursos e programas de ensino superior no Brasil. O Programa de Apoio a Planos de Reestruturação e Expansão das Universidades Federais (Reuni), criado em 2007, tem como principal objetivo o aumento das vagas de ingresso e a redução das taxas de evasão nos cursos presenciais de graduação. Por fim, a criação dos IFs, em 2008, a partir da 202 transformação dos Cefets, escolas técnicas e agrotécnicas, e a expansão pela criação de novos IFs em todo o país, temfinalidades que incidem tanto na educação profissional, quanto no ensino superior, tais como a oferta da educação tecnológica, de licenciaturas e bacharelados.

Aqui não é o espaço para aprofundar a análise de cada um desses programas, seja em sua expressão legal, na concepção particular de cada um deles ou em seus processos de implantação. Importa, sobretudo,compreender a articulação deles com o sentido geral da reforma em curso e no contexto das relações sociais, políticas e econômicas em que tal movimento ganha materialidade.

Esses programas, por se apresentarem como políticas de expansão que sugerem, em seus enunciados, a democratização do acessoa educação denível superior, como forma de promover inclusão e justiça social, operacionalizam a reconversão da educação superior de direito público a ser universalizado para uma nova concepção de ensino superior como serviço de fornecimento de uma mercadoria, seja em instituições públicas ou privadas. Os argumentos que procuram oferecer justificativa para tais programas é o da 
necessidade de urgência, eficiência e eficácia da expansão requerida como forma de ampliação do acesso das camadas mais pobres à universidade e de sua inclusão social.

Nesse sentido, a lógica operativa é a de que já que nem todos podem pagar o serviço à iniciativa privada, ao Estado cabe fazer cumprir tal necessidade, mediante o pagamento de bolsas direta ou indiretamente às organizações privadas de ensino superior. Em síntese, coadunam-se dois movimentos articulados: a conversão do direito em serviço e a conversão da educação em mercadoria, ambos operacionalizados mediante a privatização do fundo público.

Conforme Dourado (201 1, p. 53), essas iniciativas governamentaisque articulam a reestruturação e reforma da educação superior no Brasil têm sido caracterizadas pela "[...] adoção das políticas, cuja materialização tem sido marcada por expressiva expansão, interpenetração entre esferas pública e privada (privatização) e pela naturalização da diversificação e diferenciação da educação superior no país." Determinam não somente a supremacia do setor privado, mas igualmente alteram a configuração e lógica organizativa das instituições públicas, que, por meio de mecanismos diversos de controle burocrático e de condicionalidades para acesso a recursos públicos ou privados, passam a ser fortemente influenciadas e assimilam parcialmente, e em processos contraditórios de adesão e resistência, a lógica operacional dos serviços e das organizações empresariais.

Ademais, no interior desse movimento de avanço do setor privado e de reconversão conceitual e operacional do setor público, ganha relevância a constituição e progressiva influência do setor tipicamente mercantil, mediante a concentração de capitais na formação e fortalecimento de oligopólios educacionais, articulados com a abertura à internacionalização do mercado educacional, cuja manifestação mais evidente é a criação de grandes grupos, mediante consórcios entre empresas nacionais e ingressos de empresas internacionais, ampliação desses consórcios pela aquisição ou fusão com outras organizações privadas de educação superior já atuantes no mercado e pela abertura de capitais dessas empresas nas bolsas de valores.

Oestudo apresentado por Bittar e Ruas (2012, p. 1 15) conclui que a transformação da educação superior em mercadoria e a reconversão dos estudantes em "clientes-consumidores", expressam a "[...] lacuna deixada pelo Estado brasileiro nas políticas públicas, de caráter social, entre elas a 
Expansão da educação superior e da educação profissional no Brasil:tensões e perspectivas

educação, que possibilitou a hegemoniada iniciativa privada mercantil na educação superior." A lógica de constituição e funcionamento desse mercado e os seus operadores são, assim, descritos:

A mercadorização da educação superior brasileira, que tem comoessência a lógica do mercado, impulsiona, cada vez mais, empresários, hoje conhecidos como a nova burguesia de serviços educacionais, interessadosem ampliar seus negócios na área educacional e a investir maciçamente nosetor educacional. São investidores nacionais e internacionais que investemna educação superior no Brasil como um mercado promissor e altamentelucrativo, provocando movimentos de ampliação, aquisição e fusão dasIES, formando grandes oligopólios que passam a concentrar boa parte doalunado do país (BITTAR; RUAS, 2012, p. 117).

Entretanto, como ademais se caracterizam os chamados mercados emergentes, trata-se também, no caso do mercado educacional, de um mercado altamente competitivo, no qual é necessário praticar estratégias diversas de marketing e fidelização dos alunos-clientes-consumidores, bem como obter acreditação que garanta posição privilegiada frente aos demais competidores.

Nesse sentido, cumpre destacar que a avaliação desempenha papel importante no estabelecimento do modelo empresarial para a educação, em especial para a universidade, no modelo de administração de estilo empresarial, o que requer maior eficiência e eficácia no uso do recurso público ou privado, mais competência na captação de recursos extraorçamentários, a produção de mais com menos recursos e de acordo com as demandas de mercado, a submissão a avaliações de produtividade, ao estabelecimento de rankings diversos e à competitividade de mercado em busca de clientes e fontes de financiamento.

A avaliação passa, assim, a cumprir um destacado papel como mecanismo funcional à reestruturação e expansão da universidade segundo o modelo mercantil, constituindo-se como tecnologia de poder útil àrealização do processo. Nesse sentido, Sobrinho (2003, p. 31 ) destaca que "[...] sob o domínio do 'Estado avaliador' dos últimos anos, a avaliação da educação superior tem sido praticada como instrumento privilegiado de regulação. Portanto, vem exacerbando sua dimensão burocrático-legalista de controle, modelação, ajustamento e fiscalização." 
Associado a três fatores - seleção, medida e controle -, o processo de avaliação, mediante seus resultados quantificados, apresentados como resultantes de indicadores objetivos e técnicos, supostamente neutros e inquestionáveis, é operacionalizado na opinião pública, buscando legitimar perante a sociedade, rituais de premiação e punição. Tal modelo de avaliação, associado a outros fatores de financiamento e oferta de cursos, por exemplo, induzem o fortalecimento da concepção de universidade como organização operacional (e não mais como instituição social) e o desenvolvimento de práticas de heteronomia (e não mais de autonomia). Usando a conceituação de Chauí (2003), a universidade como organização passa a ser pautada pela instrumentalidade, pela lógica da adaptação dos meios ao fim particular, pela concepção e prática do saber-fazer instrumental e pela busca do resultado útil e prático, guiando-se pela prioridade na gestão, na planificação, na eficácia, sucesso e eficiência, considerados fins em si mesmo. Organização operacional, portanto, autorreferente e pautada pela agência externa do mercado.

Portanto, estabelecendo-se, a partir dessa ótica, uma nova concepção para o papel social e a ałuação da universidade, contráriasà concepção de universidade como instituição social comprometida com fins públicos e coletivamente reconhecidos, não meramente com a adaptação, mas com a reflexão crítica de seu tempo e da sociedade que a constitui e da qual é também constituinte, com a formação humana integral, com a produção da ciência e tecnologia socialmente referenciadas, o que requer o reconhecimento público de sua legitimidade e autonomia frente ao Estado e ao capital.

Quando, portanto, no contexto dos programas de reforma e ampliação, a universidade passa a assumir a caracterização de organização operacional, ela passa a negar o reconhecimento da educação superior como bem público universal e direito de cidadania, passa a afirmar a tese de que o ensino superior é serviço, similar a um bem de consumo privado, espécie de semimercadoria em um quase-mercado ou mercado educacional. Transforma-se, assim, em organização neoprofissional, heterônoma e, operacionalmente, útil à reprodução ampliada do capital. 


\section{A reforma e expansão da educação profissional}

Quando o Ministério da Educação (MEC) anunciou, em 1995, a intenção de realizar uma reforma no ensino técnico-profissional do país, utilizou-se de um discurso que atribuía à rede das então Escolas Técnicas Federais (ETFs) e Centros Federais de Educação Tecnológica (Cefets) "problemas e distorções" que apontavam três questões principais: elevado custo, formação longa e desvio da rota esperada dos egressos. Buscava-se, então, maior eficiência (redução de custos) e eficácia (maior rapidez e alcance dos objetivos).

Para tanto, o ajuste veio, a partir de 1996, após a abertura oferecida pela aprovação da Lei de Diretrizes e Bases da Educação Nacional (LDB) genérica e frouxa, mediante medidas tópicas e focadas de redefinição do marco legal. No caso, o Decreto n².208, de 17 de abril de 1997, que separava a educação profissional da educação básica no nível técnico, e instituía dois outros níveis, o básico (formação inicial e continuada, sem exigência de anterioridade de escolaridade, ou sem vínculo a processos de elevação de escolaridade) e o tecnológico (de caráter pós-médio ou superior), além de outras medidas de flexibilização quanto à formação docente, financiamento 206 e construção curricular (formadores, fontes de custeio alternativas e itinerários formativos baseados em competências, atitudes e habilidades).

Sendo assim, verifica-se que, com concepção e lógica semelhante às verificadas para a reestruturação e expansão do ensino superior analisadas no tópico anterior, a reforma da educação profissional, iniciada em 1995, constituiu um processo que - vinculado ao ideário neoliberal de redefinição do papel do Estado - representou a demissão da política pública, isto é, a redução da ação do Estado como executor de políticas públicas de caráter social. Ao privilegiar a função de gestor da implementação de políticas vinculadas aos ditames do mercado, o Estado brasileiro induziu e incentivou a constituição de um mercado privado da educação profissional, aomesmo tempo que, na esfera educacional pública, se verificavam processos complexos e diversificados de mudanças, reestruturação ou desestruturação que se abateram sobre a rede federal de Escolas Técnicas, Escolas Agrotécnicas e Centros Federais de Educação Profissional (Cefets) e sobre as redes estaduais de ensino médio e técnico-profissional.

A implantação da reforma nas instituições de educação técnica e tecnológica provocou distorções na função pública e reduziu a oferta doensino 
médio e técnico-profissional público e gratuito naquelas instituições. Por outro lado, as medidas reformadoras redefiniram a atuação daquelas instituições e incrementaram sua ação em cursos e atividades extraordinárias e pagas, desvinculadas da elevação dos níveis de escolaridade. Concretamente, por determinação do Decreto n ${ }^{\circ} 2.208$ e disposições complementares, no período de 1995 a 2002, a rede federal de escolas técnicas, agrotécnicas e Cefets reduziu 50\% a oferta de vagas do ensino médio e do ensino médio integrado à educação profissional. Para tanto, além das determinações normativas citadas, o governo utilizou-se da gestão econômico-financeira, impondo restrições e vedando o acesso a recursos àquelas instituições que resistiam à reforma, enquanto "premiava" as que a ela se subordinavam.

Paralelamente ao ocorrido na rede federal, diversas redes estaduais de educação redirecionaram a oferta de ensino médio e técnico, seja privatizando a oferta do ensino técnico, seja optando pela alternativa do pós-médio. O desvio do foco de atuação das instituições de educação profissional em âmbito federal e estadual, com a prioridade de oferta para programas e cursos de curta duração, desvinculados conceitual e operacionalmente da educação regular, foi acompanhado pela expansão da rede privada, contando inclusive com recursos dos fundos públicos.

Se o Fiese o Prouni, a partir de 1999, desempenharam papel importante na expansão privada da educação superior, o seu similar no âmbito da educação profissional é o Programa de Expansão da Educação Profissional -Proep, iniciado em 1997. Tendo como instrumentos normativos e conceituais a Lei $n^{\circ}$ 9.394, o Decreto $n^{\circ} 2.208$, as Diretrizes Curriculares Nacionais para - Ensino Médio (BRASIL, 1998) e as Diretrizes Curriculares Nacionais para a Educação Profissional de Nível Técnico (BRASIL, 1999), o Proepconstitui-se como o elemento operacional para a implantação da reforma. A análise desse programa evidencia seu papel indutor na expansão privatista da educaçãoprofissional, vistoque mais de $40 \%$ de seus recursos foram destinados aos segmentos empresariais, maquiados pelo eufemismo de "segmentos comunitários" (LIMA FILHO, 2002a). Outro programa público que permitiu o encaminhamento de parte substancial do fundo público para a iniciativa privada foi o Planfor. Ademais, o caráter marcadamente mercantil (venda de serviços, consultorias privadas etc.) assumido pelo Sistema $\mathrm{S}$ e a centralização e falta de controle sobre os recursos públicos utilizados pelas instituições desse 
Expansão da educação superior e da educação profissional no Brasil:tensões e perspectivas

sistema demonstram o fortalecimento dos segmentos empresariais com o apoio do fundo público.

Ao longo dessa fase inicial da reforma e expansão privada da educação profissional, ocorrida no período de 1995 a 2002, com resistências e contradições, também se construiu um amplo debate, em setores dos movimentos educacionais e populares, no qual se propugnava o estancamento e reversão das políticas de privatização da educação e a construção de uma nova política educacional que localizasse e integrasse a educação técnica e tecnológica, em âmbito federal e estadual, no campo de um sistema educacional público, universalizado e democratizado, em todos os níveis e modalidades.

É por força dessas demandas, que já vinha sendo apresentada mesmo antes do início do governo Lula, uma medida importante adotada pelo governo: o Decreto n 5. 154, de 23 de julho de 2004, no qual se explicitaram distintas concepções e propostas dos diversos segmentos da sociedade civil e do Estado brasileiro, expressando posições econtradições que vão da resistência à permanência, da continuidade à descontinuidade. Se, por um lado, revoga o Decreto $n^{\circ} 2.208$ e restitui a possibilidade de articulação plena 208 do ensino médio com a educação profissional, mediante a oferta integrada do ensino médio técnico, por outro lado, mantém as alternativas anteriores que haviam sido fortalecidas e ampliadas com o Decreto $n^{\circ} 2.208$ e nos programas correlatos, que expressam a histórica dualidade estrutural da educação brasileira.

Assim, ao lado da possibilidade de integração (formal, e pouco apoiada por recursos públicos e ações do governol trazida pelo Decreto $n^{\circ}$ 5. 154, manteve-se a orientação dualista e neoliberal das demais alternativas loperacional, que, como se verá, serão as privilegiadas por recursos e programas), deixando claro que a definição e condução da política educacional dependerão, fundamentalmente, das disputas que envolvem a ação do Estado, preso às determinações da macroeconomia e macropolítica de cunho liberal, em confronto comas instituições da sociedade civil organizada em luta pela construção e avanço de uma sociedade democrática e de universalização de direitos, como o direito à educação de qualidade e socialmente referenciada.

$\bigcirc$ fato é que, decorrida mais de uma década da edição do Decreto n 5. 154, a oferta da educação profissional, integrada ao ensino médio, não 
foi assumida como prioridade de política pública, tanto no âmbito da rede federal como na maioria das redes estaduais. No mesmo tempose expandiu, significativamente, a oferta de Cursos Superiores de Tecnologia e de cursos pós-médios (subsequentes), valendo lembrar que, dado o seu caráter de aligeiramento e de adequação às demandas imediatas do mundo empresarial, essas modalidades foram a opção preferencial para a expansão mercantil da educação profissional e tecnológica ${ }^{5}$.

Em trabalhos anteriores, analisou-sea reconfiguração conceitual e institucional da educação profissional e tecnológica do país, em consequência das reformas e programas empreendidos nos governos Cardoso (1995-2002) e Lula da Silva (2003-2010), destacando-se a transformação institucional das Escolas Técnicas e Agrotécnicas em Cefets, em um primeiro momento, e, posteriormente, destes em Institutos Federais de Ciência e Tecnologia e em uma universidade tecnológica federal (UTFPR) (LIMA FILHO, 2002a, 2007, 2008, 2010; SHIROMA; LIMA FILHO, 20111.

Os trabalhosacima referidos constataram, como principais resultados, do ponto de vista da análisequalitativa: a diversificação de níveis e modalidades da oferta, incluindo novas modalidades no âmbito da educação fundamental, média, superior e educação profissional, como os cursos de formação profissional inicial sem vínculo com níveis de escolaridade, os cursos pós-médios ou subsequentes e os Cursos Superiores de Tecnologia, inclusive na forma de educação a distância; a expansão quantitativa da oferta privada, bem como o esmaecimento da fronteira público-privada, com continuidade nos dois períodos analisados; a expansão geográfica e a descentralização da oferta das capitais em direção a cidades-polo; e uma diminuta expansão da oferta de EPT nas redes públicas estaduais. Um detalhamento desses resultados pode ser encontrado, entre outros, em Relatórios Finais de Pesquisa, artigos e livros publicados.

No que se refere ao estudo quantitativo em âmbito nacional, constatou-se que a oferta de educação profissional e tecnológica experimentou forte expansão na rede privada, especialmente nas modalidades de cursos superiores de tecnologia e cursos técnicos subsequentes ao ensino médio. Apesar do elemento positivo verificado na expansão da rede pública federal, saindo de 140 instituições em 2002, atingindo 354 instituições no ano de 2010, e tendo o governo federal anunciado a meta de chegar até o final de $2014 \mathrm{com}$ 562 unidades, verificou-se que, no mesmo período, o crescimento da oferta 
Expansão da educação superior e da educação profissional no Brasil:tensões e perspectivas

privada superou esses indicadores, não se alterando o histórico predomínio da oferta privada no campo da educação profissional.

As marcas históricas originárias dessa prevalência podem ser encontradas ainda nos anos de 1940, na criação dos Sistemas Nacionais da Indústria e do Comércio, evidenciando a ação patrimonialista dos representantes do capital sobre o Estado e a conquista de financiamento público para a gestão privada da educação profissional. Ao longo das décadas, a ação patrimonialista se expandiu com a configuração do chamado "Sistema S". Mais recentemente, a partir de 2011 , a expansão da educação profissional passou a ser fortemente impactada, pela criação do Programa Nacional de Acesso ao Ensino Técnico e ao Emprego (Pronatec), pelo qual se anuncia a criação entre 2011 e 2014 de 8 milhões de matrículas na educação profissional, especialmente nas modalidades de Formação Inicial Continuada (cursos de 160 horas/aula, sem vínculo com a elevação de escolaridade) e cursos técnicos de nível médio (modalidades concomitante ou subsequente, com 800 horas/aula). A análise preliminar da destinação dos vultosos recursos desse programa mostra que os principais beneficiários são, cadavez mais, as entidades do setor empresarial (Sistema $\mathrm{S}$ e grupos educacionais privados).

210 Pronatec é o programa central do governo federal para a educação profissional e devido à natureza "guarda-chuva" a ele atribuída, transformou-se, basicamente, no programa articulador, ao qual outros programas estão agregados, em âmbito federal e na articulação com as redes estaduais e municipais e com o setor privado. Sendo assim, programas importantes como - Brasil Profissionalizado (que apoia a ampliação das redes estaduais), o Programa Nacional de Integração da Educação Profissional com a Educação Básica na Modalidade de Educação de Jovens e Adultos (Proeja), a própria expansão dos institutos federais e sua oferta de educação básica e superior são diretamente afetados, uma vez que, submetidas à obrigatoriedade de oferta do Pronatec, as instituições e redes públicas desviam o foco e a ação de programas e modalidades educacionais mais consistentes que vinham sendo executados, por exemplo, a oferta do ensino médio ou da educação profissional integrada à educação básica.

Nesse sentido, se a expansão da rede pública podia ser considerada um dado positivo, vê-se que sua funcionalização ao modelo Pronatectornaasubsidiária à expansão do mercado de educação profissional. Isto porque, vinculando a educação básica oferecida na rede pública à educação 
profissional realizada no setor privado, o Pronatec efetiva-se mediante a transferência de recursos públicos para o sistema privado (seja o Sistema S ou organizações privadas de educação profissional ou educação superior, via bolsa de formação para cursos FIC de 160 horas/aula ou FIES-Técnico para cursos subsequentes ou concomitantes de 800 horas/aula). $\bigcirc$ Estado brasileiro, assim, induz e financia o fortalecimento do mercado de educação profissional.

No que concerne à clara concepção e estratégia privatizante do Pronatec, é revelador verificar os dados de sua implantação, das organizações privadas que sobressaem em sua oferta, bem como da explícita lógica mercantil que preside sua estrutura, organização e oferta.

Segundo dados do Ministério da Educação (BRASIL. MEC, 2013), no período de 2011 a 2013,foramefetivadas 3.142.469 matrículas do Pronatec $^{6}$, dentre as quais, 2.171.741 foram feitas em cursos de formação inicial e continuada (FIC), o que corresponde a $70 \%$ das matrículas do programa nessa modalidade de cursos de 160 horas/aula sem vínculo com a elevação de escolaridade. Esses dados são coerentes com as metas estabelecidas pelo governo federal para o período 2011 a 2014 , que preveem atingir o total de 7.994.775 matrículas, ou seja, oito milhões de matrículas, sendo 5,6 milhões delas em cursos FIC.

Quanto às entidades e redes ofertantes dessas matrículas, as metas estabelecem 940.040 matrículas para as redes públicas ${ }^{7}$, o que corresponde a somente $11,8 \%$ do total, enquanto a rede privada ficará com 7.054.735, isto é, $88,2 \%$ do total de matrículas, com a transferência dos recursos correspondentes a essas vagas para o Sistema $S$ ou grupos privados de educação profissional $^{8}$.

É importante destacar que a transferência maciça dos vultosos recursos do Pronatecpara a iniciativa privada é realizada para o Sistema S, entidades privadas de ensino superior e ensino técnico e também a empresas, de modo geral, que estejam interessadas em ofertar educação profissional. Nesse sentido, as possibilidades abertas pela conversão da educação profissional em "mercado emergente" atraíram a atenção de grupos e corporações nacionais e internacionais e investidores em educação, a exemplo do Grupo Kroton, conforme revelado em matéria publicada na Revista Exame de 8 de agosto de 2.013, sob o título "Kroton cria unidade de negócios para ensino técnico" em 
Expansão da educação superior e da educação profissional no Brasil:tensões e perspectivas

que o Diretor Presidente da corporação, Rodrigo Galindo, anuncia a adesão ao Pronatece declara as expectativas positivas de oportunidades de crescimento no ramo: "Estamos entrando fortemente nessa indústria, num jogo que a gente sabe jogar [...]" (KROTON, 2013), concluiu o investidor.

O sitio eletrônico dessa corporação econômica apresenta uma definição reveladora da concepção mercantil de cursos técnicos:

Os cursos técnicos têm como objetivo capacitar o participante para atuar no setor produtivo, com um ensino focado e rápido. Seu diferencial está nos conhecimentos práticos, ao apresentar métodos e experiências do cotidiano empresarial. $O$ curso técnico é focado na empregabilidade. O participante tem acesso imediato ao mercado de trabalho (KROTON, 2014a, grifos nossos).

Essa corporação e muitas outras ${ }^{9}$ receberam a autorização de oferta de cursos do Pronatec, mediante credenciamento via Sistema Sistec, do Ministério da Educação, conforme "Comunicado ao Mercado", divulgado no sitio eletrônico:

No total, a Kroton recebeu a autorização para preencher 22.992 vagas, sendo 13.464 para o período matutino, 6.760 para o período vespertino e 2.768 para o período noturno, as quais serão oferecidas por meio de 41 diferentes cursos e em 30 Instituiç̧ões de Ensino. Cabe lembrar, também, que essas vagas são referentes à modalidade Bolsa Formação, a qual oferece bolsas de estudos totalmente subsidiadas pelo Governo Federal. As vagas aqui anunciadas terão suas aulas iniciadas já neste primeiro semestre de 2014 (KROTON, 2014).

Em seminário realizado em Brasília, no início de 2014, sob o sugestivo título "Por que montar uma escola técnica", entidades de consultoria e grupos de investidores demonstram sua atenção ao "promissor" mercado da educação profissional, ressaltando que os programas governamentais de financiamento são a "bola da vez" dos investimentos em educação e enumerando vantagens comparativas dessa inversão, dentre as quais, destacam: evitam salas ociosas; otimizam custo fixo; melhoram fluxo de caixa; têm pouca inadimplência; divulgam e fortalecem a marca; crescimento rápido da escola; fidelização dos alunos para outros cursos (NEWEDUCATION, 2014). 
A constatação da presença e forte da atuação desses grupos econômicos na expansão da educação profissional mostra semelhança e coordenação com o movimento verificado na expansão da educação superior, inclusive com a coincidência de várias das empresas, corporações e oligopólios identificados no estudo de Bittar e Ruas (2013).

Trata-se aqui de reiterar que, tal como o analisado para a educação superior, a expansão da educação da educação profissional, se realizada mediante a realização da educação como direito, pelo fortalecimento do setor público e na concepção de formação humana integral, cumpriria papel social relevante e necessário para a efetiva democratização da sociedade brasileira. No entanto, de acordo com nossa análise, a expansão que, efetivamente, ve mocorrendoviaPronatecdesconsidera essas e outras questões fundamentais da educação profissional e tecnológica, tais como:a integração com a educação básica com compromisso de elevação de escolaridade dos trabalhadores, a articulação com a educação superior, a formação inicial e continuada de professores, o financiamento público para a educação pública e a pesquisa. Pelo contrário, nossa análise evidencia que a realização da expansão via Pronatecfortalece a lógica mercantil, o direcionamento do projeto educacional pela lógica do capital humano e da inclusão subordinada e, por fim, a produção de "estatísticas favoráveis" de ampliação da oferta educacional.

Na pesquisa sobre "A reforma da educação profissional, nos anos noventa", apresentada como Tese de Doutorado, na Universidade Federal de Santa Catarina (UFSC), Lima Filho (2002) concluiu que se evidenciava a articulação entre a reforma da educação profissional, o processo de reforma do Estado brasileiro e as transformações das relações sociais capitalistas no contexto da globalização. Constatava-se que a reforma educacional, sob o argumento da expansão, diversificação e flexibilização da oferta de educação profissional, contribuía para a promoção de modalidades educacionais alternativas ou substitutas da educação básica, para a diversificação e segmentação social dos sistemas educacionais de nível médio e superior e para estabelecer uma situação de ambiguidade, na qual a instituição pública reduzia sua oferta de educação regular e incrementava sua ação em atividades extraordinárias e pagas, como estratégia de autossustentação financeira.

A tese de Lima Filho (2002) evidencia que adualidade, histórica no ensinomédio, agora se estendia ao ensino superior por meio de cursos de tecnologia, de menor duração, destituídos de aprofundamento científico e 
Expansão da educação superior e da educação profissional no Brasil:tensões e perspectivas

tecnológico, limitados à atividade de ensino dissociada da extensão e da pesquisa, focados na prática e no pragmatismo utilitarista de mercado, constituindo um modelo de ensino superior de baixo custo. Concluía-se que a reforma e expansão da educação profissional se constituía emumaestratégia de utilização de recursos públicos para a desestruturação e empresariamento da instituição pública e para a promoção do mercado privado de educação profissional (LIMA FILHO, 2002).

Em trabalhos mais recentes ("O ensino superior nas instituições federais de educação tecnológica: situação atual, desafios e perspectivas", financiado pelo CNPq, de 2005 a 2008, e "Expansão e reconfiguração institucional da educação profissional e tecnológica no Estado do Paraná: concepções, programas e ações", financiado pela Fundação Araucária, 2011 a 2014) as conclusões a que se chegouindicam que o Estado brasileiro, mediante a expansão da educação profissional via Pronatec, delega às entidades patronais e aos grupos educacionais privados a realização da educação profissional - e financia o processo -, concedendo-thes o direito sobre a concepção de formação a ser materializada, induz a uma real expansão da rede privada de EPT e de educação superior, com transferência direta de recursos públicos para o

214 financiamento de organizacionais empresariais e expansão e fortalecimento do mercado educacional.

Pelo exposto até aqui sobre a educação profissional, conclui-se que a natureza da expansão e transformações em curso, desde meados da década de 1990 à atualidade, tanto doponto de vista quantitativo, pela expansão das instituições e da oferta, quanto do ponto de vista qualitativo, pela "nova institucionalidade", diversidade de programas e modalidades ofertadas, apresenta fortes elementos de continuidade e aderência conceitual e operacional às orientações de caráter neoliberal e que, no caso brasileiro, configuramreiteração e atualização da tendência histórica de constituição de um modelo especifico de educação profissional e tecnológica, paralelo ao sistema educacional geral básico e superior, marcado pelo pragmatismo e imediatismo funcional às demandas específicas do capital. 


\section{A educação superior e educação profissional nos marcos da disputa de projetos societários: desafios}

capitalismo é tipicamente um modelo societário de contradição e conflito, marcado pelas relações antagônicas entre capital e trabalho. Antagonismos que se materializam em diversas dimensões sociais, como as disputas em torno de projetos sociais, nos quais se inserem os projetos educacionais, dentro deles, as reformas, políticas, programas e a atuação das instituições sociais. Portanto, é preciso ter em mente que a identidade e o papel social da universidade pública e das instituições de educação profissional e tecnológica (EPT) são disputados pelas diferentes forças sociais. Essas disputas ocorrem, de fato, embora, na maioria das vezes, isso seja dissimulado, ideologizado com mensagens/manifestações generalistas ou abstratas, tais como "vivemos um apagão de mãodeobra", "é urgente capacitar, e curso longo não resolve", "as empresas clamam por trabalhadores qualificados", "nem todo os que vão à universidade tem tempo, condições e/ou interesse de fazer pesquisa etc.", "frequentar um curso do Pronatec vai ser motivador para ele (trabalhador) vir outra vez fazer um curso mais denso", "o laboratório montado pela/para a empresa vai ser muito útil também para outras finalidades além das da empresa", "com oito milhões de vagas no Pronatec vamos resgatar a dívida social" etc., etc., etc.

Ora, o que se disputa? Duas coisas fundamentais: 1) a operacionalidade dos sistemas educacionais, sua funcionalização às demandas imediatas do capital e a adequação da reprodução da força de trabalho ao processo de valorização do capital lo que faz e como faz no imediatoda atividade de produção); 2) a subjetividade do trabalhador e do cidadão (o que deve pensar, como deve se reconhecer, seus valores, nas relações de mediação no trabalho e entre este e outras dimensões da sociabilidade). Para o desenvolvimento das forças produtivas, sob o domínio do sistema capital, a educação e a formação profissional são funcionalizadas como formas de domínio úteis e necessárias à concorrência intercapitalista para a captura da operacionalidade e da subjetividade dos trabalhadores. Precisamente por isso, o caráter classista da educação superior e da educação profissional e tecnológica se torna mais agudo. Do ponto de vista do capital, trata-se, antes que formar ou educar os trabalhadores, de CONFORMAR, fazer a adequação da força de trabalho aos seus objetivos, promovendo tipos específicos de educação 
superior e formação profissional como estratégia de subordinação, tendo em vista a valorização do capital. Mas, se a CONFORMAÇÃO é importante para o capital, a educação é central para a classe trabalhadora, como forma de conhecer inclusive os modos como a sociedade capitalista funciona e os explora e como forma de conhecimento importante para desenvolver estratégias de luta por outra sociedade.

Em uma sociedade de classes, a expansão da educação básica, superior, técnica e tecnológica cumpre objetivos estratégicos e contraditórios, podendo atender a interesses distintos e/oucontrários, tanto para o capital, quanto para o trabalho. Assim, conforme Marcuse (1979), o domínio da ciência e da tecnologia, dependendo de sua concepção e/ou utilização, pode servir a polos contrários: tanto pode contribuir com a manutenção e recrudescimento do trabalho árduo e da alienação do trabalhador, quanto contribuir para a sua emancipação e a fruição plena da vida.

Como, então, construir uma identidade social da educação superior e da EPTque atenda aos interesses da classe trabalhadora e que, portanto, seja voltada para a formação humana integral, científica e tecnológica, ético-política? Quais os limites e possibilidades, especificamente na sociedade 216 brasileira, uma sociedade que, como definiuOliveira (2003), historicamenteproduz a exclusão e se retroalimenta dela? Cabe pensá-las /a educação superior e a EPT) como parte da estratégia de luta em favor dos trabalhadores em direção aoutra sociedade?

Evidente que sim, pois o que existediante de nós são projetos societários em disputa. É importante entender a disputa pela identidade, o papel social e a própria expansão da educação superior e da EPT como parte das lutas dos trabalhadores, no contexto de disputa de projetos, para uma sociedade e uma educação para além do capital (MÉSZAROS, 2005).

Nesse sentido, hoje no Brasil, trava-se uma disputa forte de projetos educacionais. Na educação, de modo mais amplo, o Plano Nacional de Educação (PNE) para o período 2014-2024 (Lei n¹ 3.005, de 25 de junho de 2014 ), tende para olado conservador e uma das grandes evidências é o incentivo às parcerias público-privado e a abertura para a transferência de recursos públicos para o setor privado. Na verdade, aí também trata-se da disputa de projetos sociais educacionais em que o capital mostra o seu poder, privatizando o público estatal. Conforme analisado, nos tópicos anteriores, os 
denominados "parceiros" são, na realidade, grupos econômicos, disfarçados de filantropos, porém atuando em defesa de seus interesses imediatos da reprodução do capital investido ou de apropriação do capital transferido pelo fundo público, ou, ainda, com interesses mediatos, atuando como intelectuais orgânicos do capital por dentro dos sistemas educacionais.

Essasituação, evidentemente,não é fruto de uma fatalidade, mas do tipo de sociedade e de desenvolvimento que foi sendo definido historicamente e que impediram e impedem a efetiva universalização da educação, no país, vistoque a burguesia brasileira nunca colocou, em termos concretos, a conclusão da educação básicacom qualidade, a formação técnico-profissional e a educação superior para a maioria dos trabalhadores, sequer, para prepará-los para o trabalho complexo.

A quantidade, quandoocorredestituída de qualidade, no âmbito da garantia dos direitos, como o direito educacional, como tem sido historicamente conduzida a política educacional brasileira, em que reiteradamente a ampliação da oferta e acesso das camadas populares a níveis educacionais mais elevados se faz com a perda da qualidade da educação, é, antes que realização do direito, a sua negação. Trata-se, portanto, na perspectiva já apontada por Gramsci (1979), de qualificar a quantidade.

No embate de projetos societários, situa-se, atualmente, a definição da identidade e do papel social da educação superior e da EPT e sua expansão. No projeto societário que combina concentração de riqueza e desigualdade dentro de uma ótica modernizadora que abre novas fronteiras ao capital mundial não se coloca como necessidade a universalização com qualidade socialmente referenciada da educação superior e da EPTtampoucoas bases materiais para que ela se efetive com qualidade. $O$ projeto de desenvolvimento dominante pauta-se pela lógica da modernização conservadora e da financeirização, o que significa abertura de fronteiras ao capital internacional. Nessa ótica, a expansão da educação, não como direito, mas como mercadoria (serviço, na lógica mercantil) significa garantias ao livre mercado e ao lucro garantido pela apropriação privada do fundo público.

No plano da concepção e da prática, pautam-se por uma visão pragmática, fragmentária, inovacionista e produtivista de ciência e conhecimento sob a ótica das "competências para a empregabilidade", noções que refinam o fetiche da ideologia do capital humano. O lema e as ações que orientamtal 
Expansão da educação superior e da educação profissional no Brasil:tensões e perspectivas

reforma e expansão, desde sua origem, e que serve aos industriais, ao mundo dos negócios, enfim, ao mercado e ao capital, é transposto para a educação básica, para o ensino superior e também para a educação profissional, determinando, transversalmente, sua heteronomia e funcionalidade.

A resistência e a contraposição a este projeto é fundamental, do ponto de vista da classe trabalhadora e das forças sociais que lutam por um projeto verdadeiramente sustentável de desenvolvimento que efetive as reformas sociais de base, democratize o acesso à riqueza socialmente produzida e incluatodos os brasileiros na cidadania efetiva. Para que a universalização da educação se efetive com qualidade, é necessário dotar as instituições de infraestruturas adequadas, projetos políticos pedagógicos socialmente referenciados, gestão democrática, com autonomia e instâncias participativas, com trabalhadores e movimentos sociais e populares, quadros de docentes e técnicos educacionais adequados em quantidade e qualidade, capacitados mediante processos de formação inicial e continuada amplos e permanentes, com planos de carreiras, salários e condições de trabalhos dignos.

As políticas expansionistas são implantadas cada vez mais verticalmente, sem participação da comunidade em seu processo de concepção e 218 decisão de implantação. Com isso, produz-se o crescimento da burocracia e de seu poder centralizador em detrimento de relações democráticas. Essa é, de certo modo,uma condição necessária para a implantação de programas nos quais se observam uma sobrecarga de trabalho acentuada. Não é àtoa que pesquisas e sindicatos apontam o crescimento da incidência de doenças do trabalho na educação. Na lógica do produtivismo acadêmico, o professor, o pesquisador é levado a incorporar o trabalho como "sua droga cotidiana, sua paixão" e "[...] o adoecer torna-se, para muitos professores, a única forma de resistência às suas novas funções na universidade $[\ldots]^{\prime \prime}$, envoltos em um ambiente marcado pela competitividade e fragilização da coletividade (SGUISSARDI; SILVA JÚNIOR, 2009, p. 43).

Portanto, caberia discutir mais profundamente as formas de materialização e os desdobramentos dessa reforma e expansão daeducação superior e da EPT e de como se situam frente aos principais desafios/problemas da educação básica, profissional e superior na atualidade. Dentretaisdesafios, destacam-se: 1. Ampliação, capilarização e publicização da rede pública; 2. Configuração de um sistema nacional de educação, público e integrado, da educação básica e superior, no interior do qual se localizaria a educação profissional; 3. 
Valorização dos profissionais da educação; 4. Pesquisa e produção do conhecimento centradas em tecnologia sociais e nas demandas locais, em diálogo com os movimentos sociais; 5 . Financiamento público permanente e adequado para as instituições educacionais públicas.

Considerandoo enfrentamentodesses desafios, valereafirmar, como consideração final, a centralidade do embate por um projeto educacional, no qual se insere a universidade pública e a EPT, que supere as regressõessociais das reformas sociais em curso, plasmadas na fragmentação da educação, no pragmatismo e nas antinomias entre a formação prática, utilitária e imediata a serviço da adequação do capital e a ordem estabelecida, em detrimento da formação humana integral de sujeitos dotados de capacidade de autonomia, reflexão, crítica e ação para a transformação. Retomar essa perspectiva de projeto societário é situar-se ao lado das forças sociais que buscam, na mediação da educação, contribuições decisivas para a construção de uma sociedade que garanta a produção e apropriação social da riqueza, do conhecimento científico e tecnológico e da arte e cultura para todos.

\section{Notas}

1 Texto apresentado como Conferência de Abertura do XXII Seminário Nacional Universitas/Br, realizado na Universidade Federal do Rio Grande do Norte, em Natal/RN, de 21 a 23 de maio de 2014.

2 Estes foram os eixos temáticos do XXII Seminário Nacional Universitas/Br.

3 Para aprofundamento sobre as influências do neoconservadorismo nas políticas educacionais brasileiras, como elementos conceituais da agenda pós-moderna, ver o artigo "O renovado conservadorismo da agenda pós-moderna", de Maria Célia Marcondes de Moraes (2004).

4 Para aprofundamento, ver o artigo "Ceticismo epistemológico, ironia complacente: indagações acerca do neopragmatismo de Richard Rorty", de Maria Célia Marcondes de Moraes (2003).

5 Segundo o Inep, os Cursos Superiores de Tecnologia foram a modalidade que apresentou maior taxa de crescimento na expansão da educação superior brasileira nos últimos anos. A Sinopse Estatística da Educação Superior indica que em 2012 existiam 5.969 Cursos Superiores de Tecnologia, dos quais 4.852 estão na rede privada, o que corresponde a 81,3\%. No tocante às 994.804 matrículas nestes cursos, 803.969 delas estão na rede privada, correspondente a 80, 8 \% (BRASIL; MEC; INEP, 2013).

6 Dados acumulados até abril de 2013 (BRASIL. MEC, 2013).

7 Aquiestãoincluídosos cursos ofertados pela rede federal, pelas redes estaduais mediante o Programa Brasil Profissionalizado e pelo Programa E-TEC Brasil. 
Expansão da educação superior e da educação profissional no Brasil:tensões e perspectivas

8 O Orçamento previsto para o Pronatec, no período de 2011 a 2014, é, aproximadamente, de 24 bilhões de reais (BRASIL, 2012).

9 Destacam-se, pela quantidade de vagas ofertadas pelo Pronatec, os grupos educacionais Kroton e Estácio de Sá, entre outros. A relação de ofertas e a matrícula nos cursos realizados pelos grupos privados com bolsa formação financiada pelo Programa Pronatecpode ser acessada pelos seguintes sítios do Ministério da Educação: http:/ / sistec.mec.gov.br e http:/ / sisutec.mec.gov.br.

\section{Referências}

BITTAR, Mariluce; RUAS, Claudia Mara Stapani. Expansão da educação superior no Brasil e a formação dos oligopólios - hegemonia do privado mercantil. Eccos Revista Científica, São Paulo, n. 29, p. 115-133, set./dez. 2012.

BRASIL. Lei n 9.394, de 20 de dezembro de 1996. Estabelece as Diretrizes e Bases da Educação Nacional. Diário Oficial [da] República Federativa do Brasil, Poder Executivo, Brasília, DF, 23 dez. 1996. Seção 1, p. 27.833,

Decreto $n^{\circ} 2.208$, de 17 de abril de 1997. Regulamenta o parágrafo 2o do art. 36 e os artigos 39 a 42 da Lei n 9.394, de 20 de dezembro de 1996, que estabelece as diretrizes e bases da educação nacional. Diário Oficial [da] República Federativa do Brasil, Poder Executivo, Brasilia, DF, 18 abr. 1997, Seção 1, p. 7760.

Lei n ${ }^{\circ}$ 10.172, de 9 de janeiro de 2001. Aprova o Plano Nacional de Educação e dá outras providências. Diário Oficial [da] República Federativa do Brasil, Poder Executivo, Brasília, DF, 10 jan. 2001, Seção 1, p. 1.Disponível em: http://www.planalto.gov.br/ ccivil_03/leis/leis_2001/110172.htm. Acesso em: 25 ago. 2014.

Decreto $n^{\circ}$ 5.154, de 23 de julho de 2004. Regulamenta o $\S 2^{\circ}$ do art. 36 e os arts. 39 a 41 da Lei n 9.394, de 20 de dezembro de 1996, que estabelece as diretrizes e da educação nacional e dá outras providências. Diário Oficial [da] República Federativa do Brasil, Poder Executivo, Brasília, DF, 26 jul. 2004, Seção 1, p. 18. Disponível em:http: / / www.planalto.gov.br/ccivil_03/_ato20042006/2004/decreto/d5 154.htm. Acesso em: 10 ago. 2014.

Lei $n^{\circ} 13.005$, de 25 de junho de 2014.Aprova o Plano Nacional de Educação - PNE e dá outras providências. Diário Oficial [da] República Federativa do Brasil, Poder Executivo, Brasília, DF, Edição extra 26 jun 2014, Seção 1, p. 1. Disponível em:http:// www2.camara.leg.br/legin/fed/lei/2014/lei-1 3005-25-junho-20 14-778970-publicacaooriginal-144468-pl.html. Acesso em: 25 ago. 2014. 
Parecer n. 15, de 1 de junho de 1998. Diretrizes Curriculares Nacionais para o Ensino Médio. Brasília, 1998. Diário Oficial [da] República Federativa do Brasil.cnte.org. br:8080/legislacao-externo/rest/lei/49/pdf. Acesso em: 25 ago. 2014

Parecer n. 16, de 5 de outubro de 1999. Diretrizes Curriculares Nacionais para a Educação Profissional de Nivel Técnico. Brasília, 1999. Diário Oficial [da] República Federativa do Brasil, Poder Executivo, Brasília, DF, 26 nov. 199, Seção 1, p. 229. Disponível em: http://portal.mec.gov.br/cne/arquivos/pdf/1999/pceb016_99.pdf. Acesso em: 25 ago. 2014

Ministério da Educação. Educação profissional e o PRONATEC. Secretaria de Educação Profissional e Tecnologia. Diretoria de Integração das Redes de EPT lapresentação). Fortaleza, 2013. Disponível em: http://www.cee.ce.gov.br/phocadownload/ apresentacoes/ppt-forumcee-fortaleza-03-06-13-v2.pdf. Acesso em: $1^{\circ}$ set. 2014

Ministério da Educação. Instituto Nacional de Estudos e Pesquisas Educacionais Anísio Teixeira. Censo da educação básica -resumo técnico, 2012. Disponível em: http:// www.inep.gov.br. Acesso em: 25 ago. 2014.

Sinopses estatísticas do censo da educação superior: 2013. Brasília: MEC. Disponível em: http://www.inep.gov.br/superior/censosuperior/sinopse/default.asp. Acesso em: 10 fev. 2014.

MEC. Secretaria Executiva. Subsecretaria de Planejamento e Orçamento. Relatório de avaliação - plano plurianual - 2008-201 1. Brasília, MEC, 2012. (Avaliação setorial. Exercício 2012 . Ano base 2011 l). Disponível em:http://www.mec.gov.br. Acesso em: 25 ago. 2014.

CATANI, Afrânio Mendes; OLIVEIRA, João Ferreira de. As políticas de diversificação e diferenciação da educação superior no Brasil: alterações no sistema e nas universidades públicas. In: SGUISSARDI, Valdemar (Org.). Educação superior: velhos e novos desafios. São Paulo: Xamã, 2000.

CHAUÍ, Marilena. A universidade pública sob nova perspectiva. Revista Brasileira de Educação, Rio de Janeiro, n. 24, p. 5-15, set./dez. 2003.

DOURADO, Luis Fernandes. Reforma do Estado e as políticas para o ensino superior no Brasil nos anos 90. Educação \& Sociedade, Campinas, v. 23, n. 80, p. 234-252, set. 2002.

Políticas e gestão da educação superior no Brasil: múltiplas regulações e controle.

Revista Brasileira de Política e Administração da Educação, Recife, v. 27, n. 1, p. 53-65, jan./abr. 2011. 
Expansão da educação superior e da educação profissional no Brasil:tensões e perspectivas

GRAMSCl, Antonio. Os intelectuais e a organização da cultura. Rio de Janeiro: Civilização Brasileira, 1979.

KROTON. Comunicado ao mercado. 2014. Disponível em:http://ri.kroton.com.br/kroton2010/web/mobile/conteudo_mobile. asp?tipo=32868\&id=188648\&idioma=0\&co nta $=28$. Acesso em: 22 abr. 2014 .

Nossos cursos. Cursos técnicos. 2014a. Disponível em:http://www.guiapronatec. com.br/perguntas-frequentes/. Acesso em: 22 abr. 2014.

LIMA FILHO, Domingos Leite. A reforma da educação profissional no Brasil nos anos noventa. 2002. 380f. Tese (Doutorado em Educação)- Programa de Pós-Graduação em Educação, Universidade Federal de Santa Catarina, Florianópolis, 2002.

Impactos das recentes políticas de educação e formação profissional. Perspectiva, Florianópolis, v. 20, n. 02, p. 269-301, jul./dez.2002a.

A Universidade Tecnológica entre o público e o privado: pragmatismo e determinismo tecnológico na reforma da educação superior. In: SILVA JúNIOR, João dos Reis (Org.). O pragmatismo como fundamento das reformas educacionais no Brasil. São Paulo: Átomo \& Alínea, 2007.

Contribuição para a análise de reformas educacionais: teoria e ideologia sob a hegemonia do Estado neoliberal. In: TUMOLO, Paulo Sérgio; BATISTA, Roberto Leme (Org.). Trabalho, economia e educação: perspectivas do capitalismo global. Maringá: Práxis, 2008.

O PROEJA em construção: enfrentando desafios políticos e pedagógicos. Educação \& Realidade, Porto Alegre, v. 35, n. 1, p. 109-127, jan./abr. 2010.

MARCUSE, Herbert. La angustia de Prometeo (25 tesis sobre técnica y sociedad). El viejo topo, Barcelona, n. 37, p. 43-44, oct. 1979.

MÉSZÁROS, Istrán. Educação para além do capital. São Paulo: Boitempo, 2005.

MORAES, Maria Célia Marcondes. O renovado conservadorismo da agenda pós-moderna. Cadernos de Pesquisa, São Paulo, v. 34, n. 122, p. 337-357, maio/ago. 2004.

NEW EDUCATION. Seminário PRONATEC. Por que montar uma escola técnica. 2014. Disponível em:http://www.neweducation.com.br/. Acesso em: 22 ago. 2014.

OLIVEIRA, Francisco. Crítica à razão dualista: o ornitorrinco. São Paulo: Boitempo, 2003. 
KROTON cria unidade de negócios para ensino técnico. Revista Exame. São Paulo, 8 ago. 2013. Disponível em:http://exame.abril.com.br/negocios/noticias/kroton-cria-unidade-de-negocios-para-ensino-tecnico-2. Acesso em: 22 abr. 2014.

SGUISSARDI, Valdemar; SILVA JÚNIOR, João dos Reis. Trabalho intensificado nas federais: pós-graduação e produtivismo acadêmico. São Paulo: Xamã, 2009.

SHIROMA, Eneida Oto; LIMA FILHO, Domingos Leite. Trabalho docente na educação profissional e tecnológica e no PROEJA. Educação \& Sociedade, Campinas, v. 32, n. 116 , p. 725-743, jul./set. 2011.

SILVA JÚNIOR, João dos Reis; SGUISSARDI, Valdemar. Novas faces da educação superior no Brasil: reformas do Estado e mudanças na produção. Bragança Paulista: EDUSF, 1999.

Reforma da educação superior no Brasil: renúncia do Estado e privatização do público. Revista Portuguesa de Educação, Braga, v. 13, n. 2, p. 81-1 10, 2000.

SOBRINHO, José Dias. Avaliação da educação superior: regulação e emancipação. Avaliação: Revista da Rede de Avaliação Institucional da Educação Superior, Sorocaba, v. 8, n. 1, p. $31-47$, mar. 2003 .

Prof. Dr. Domingos Leite Lima Filho Universidade Tecnológica Federal do Paraná

Programa de Pós-Graduação em Tecnologia e Sociedade Coordenador do Grupo de Estudos e Pesquisas em Trabalho, Educação e Tecnologia | GETET Email |domingos@utfpr.edu.br Recebido 25 nov. 2014 Aceito 11 fev. 2015 